\title{
To study the effect and mechanism of dimethyl fumarate [DMF] in adjuvant induced arthritis model in rats
}

\author{
Shruti Saha ${ }^{1}$, Lekha Saha ${ }^{1 *}$, Neha Singh ${ }^{1}$, Jagjit Singh ${ }^{1}$, Rohit Kumar $^{1}$, Alka Bhatia ${ }^{2}$, Amitava Chakrabarti ${ }^{1}$ \\ ${ }^{1}$ Department of Pharmacology, PGIMER, Chandigarh, India. ${ }^{2}$ Department of Experimental Medicine and \\ Biotechnology, PGIMER, Chandigarh, India.
}

\begin{abstract}
Currently available disease modifying anti-rheumatoid drugs have limitations like dose-dependent toxicity and tolerance. Dimethyl fumarate has demonstrated anti-inflammatory and immunomodulatory properties in various animal models. Thus, the present study aimed to evaluate the effects and mechanism of DMF in a murine model of adjuvant-induced arthritis.

A total of 84 rats were divided into early treatment groups $(n=48)$ and late treatment groups $(n=36)$. There were 8 subgroups and 6 subgroups ( $\mathrm{n}=6$ in each group) in the early and late treatment groups, respectively. Experimental rheumatoid arthritis (RA) was induced in Wistar rats by injecting complete Freund's adjuvant (CFA) intradermally at the base of the tail. Antirheumatic effects were evaluated by arthritis and histopathological scoring of ankle joints. To evaluate anti-oxidant properties, GSH, catalase, SOD, and lipid peroxidation were measured. ESR, WBC count, TNF- $\alpha$ and IL-6 levels were measured to evaluate the immunomodulatory properties of DMF. DMF demonstrated anti-inflammatory effects by decreasing arthritis and histopathological scores compared to the CFA control group, though the difference was not statistically significant. DMF exhibited immunomodulatory properties as decreases in TLC count, serum TNF- $\alpha$, and plasma IL-6 levels were observed. In all the above-mentioned parameters, the best response was achieved with the early combination therapy of DMF $30 \mathrm{mg} / \mathrm{kg}$ and methotrexate [Mtx] $0.1 \mathrm{mg} / \mathrm{kg}$. In the present study, DMF demonstrated antirheumatoid effects in a rat model of CFA-induced arthritis. The best antirheumatoid effect was achieved with the early combination of DMF and Mtx.
\end{abstract}

Keywords: Anti-inflammatory agents, Antioxidants arthritis, Dimethyl fumarate, Freund's adjuvant, Rheumatoid

\section{Introduction}

Rheumatoid arthritis [RA] is a chronic inflammatory autoimmune connective tissue disease which characteristically causes the gradual ongoing destruction of articular cartilage and resorption of bone, leading to disability and premature mortality [1-3]. It is the most common form of polyarticular inflammatory arthritis [1], and multiple epidemiological studies determined the 2000 2015 incidence rate to be 18.5 cases per 100,000 personyears; the prevalence was $0.329 \%$ by January 2015 [4]. According to Handa et al., in 2015, the prevalence of RA in India was $0.2-0.75 \%$ [5].

RA has been a widely-studied disease over the years, and numerous animal models have been developed to understand the pathogenesis of the disease and the effects and mechanisms of various drugs used to treat it. Adjuvantinduced arthritis [AIA] is one of the oldest models developed. Different adjuvants have been successfully used in producing AIA [6]. Among them, complete Freund's adjuvant (CFA) is most commonly used, as the development of this RA model is easy and has been standardized over the years [6].

At present, several disease modifying antirheumatoid drugs [DMARDs] are available for the treatment of RA, but all of these agents have limitations in terms of adverse effects or cost effectiveness. Methotrexate [Mtx] is used commonly [72\%] in either combination therapy or monotherapy, followed by sulfasalazine [28\%], hydroxychloroquine [17.6\%], leflunomide [16.8\%],

chloroquine [13.6\%], and azathioprine [3.7\%] [7]. Biologic agents available are abatacept, etanercept, golimumab, infliximab, rituximab and tocilizumab, adalimumab, and certolizumab pegol [8]. In Mtx therapy, 20-40\% patients either do not respond or develop toxicity [9].

All the above-mentioned drugs used in the treatment of RA have the common problem of dose-related toxicity. Gold and penicillamine are now obsolete owing to their toxicity. Oral auramine salts caused colitis, while severe

Personal non-commercial use only. Rheumatology Research Journal. Copyright @ 2020 . All rights reserved

*Corresponding Author: Dr. Lekha Saha, Professor, Department of Pharmacology, Fourth Floor, Research Block B, PGIMER, Chandigarh, India., E-mail: lekhasaha@ rediffmail.com, Telefax+919463503752.

Received: 21 January 2020; Accepted: 06 April 2020 
renal impairment was caused by both gold salts and penicillamine. Sulphasalazine was withdrawn from use after its introduction, reintroduced in the late 1970s, and again withdrawn due to its toxicities, including gastrointestinal intolerance, hepatotoxicity, leukopenia, and rash. Nephrotoxicity is the main limitation of cyclosporine apart from malignancy, gastrointestinal intolerance, and paraesthesia. Suppression of bone marrow and increased risk of infection are the main limitations of azathioprine. Though Mtx is most effective in RA, its use is limited by its toxicity profile which includes gastrointestinal intolerance, hepato-renal impairment, bone marrow suppression leading to leucopoenia, pulmonary fibrosis, and pneumonia. Biologics are costly, thus causing the common problem of cost-effectiveness. Increased risk of infection and bone marrow suppression are other common limitations of biologics. Apart from these, some biologics, like tocilizumab and tofacitinib, also lead to elevation of hepatic enzymes [7, 8, 9]. Hence, there is a need to develop an ideal drug which can act as an effective DMARD, have a minimum toxicity profile, and last but not least, be available at a price which most patients can afford.

The complex pathogenesis of RA has been studied over the years, and various hypotheses have been developed which can be grossly divided into autoimmune and inflammatory pathways. The factors that can lead to RA include inflammatory cascades, increased levels of tumor necrosis factor $\alpha$ (TNF- $\alpha$ ), interleukins (IL-1b and IL-17), as well as reduced levels of nuclear factor-erythroid 2related factor-2 (Nrf2) [10].

Recently, it was found that the nuclear factor $\kappa \mathrm{B}$ $(\mathrm{NF} \kappa \mathrm{B})$ pathway plays a major role in the pathogenesis of RA. NF $\kappa$ B is a promoter of the TNF- $\alpha$ gene which plays a major role in regulating the production of proinflammatory cytokines which result in inflammation of the joints [11].

In most tissues, cells are exposed to frequent changes in levels of oxidative stress and inflammation. Nuclear factor (erythroid-derived 2)-like 2 (Nrf2) and nuclear factor- $\kappa \mathrm{B}$ $(\mathrm{NF}-\kappa \mathrm{B})$ are key transcription factors that regulate cellular responses to oxidative stress and inflammation, respectively. Pharmacological and genetic studies have suggested that there is functional cross-talk between these two important pathways. The absence of Nrf2 can exacerbate NF- $\kappa \mathrm{B}$ activity, leading to increased cytokine production, whereas $\mathrm{NF}-\kappa \mathrm{B}$ can modulate $\mathrm{Nrf} 2$ transcription and activity, having both positive and negative effects on the target gene expression [12].

Dimethyl fumarate [DMF] [also known as BG-12], fumaric acid ester, has been used to treat psoriasis since 1994. The US FDA approved DMF for the treatment of remitting-relapsing multiple sclerosis [RRMS] in March 2013 [FDA approves new multiple sclerosis treatment: Tecfidera. FDA news release. 2013; Available from: http://www.fda.gov/NewsEvents/Newsroom/PressAnnoun cements/ucm345528.htm].

DMF is a prodrug, and after oral ingestion it is metabolized into the active metabolites monomethyl fumarate $[\mathrm{MMF}]$ and fumarate. Mechanistic studies on DMF have been performed over the years, and it has been proposed that DMF presents anti-inflammatory, antioxidant, and immunomodulatory properties through activation of the Nrf2 pathway which, in turn, suppresses NF $\kappa B$ activation $[13,14,15,16,17]$. On an extensive literature search, only one animal study was found in the published literature which has demonstrated the effect of DMF in an animal model of RA [18]. This study was conducted on a murine model of collagen-induced arthritis (CIA) and reported a dose-dependent decrease in disease score in the CIA model. A multicentric phase 2 clinical trial was also found to be registered under clinicaltrial.gov in December 2008, last updated on September 2013; however, no study results were found [19].

Hence, the effects of DMF on RA have not yet been established, nor has the mechanism of action of DMF in RA been studied. Evidence of the efficacy of DMF in combination with other DMARDs, like Mtx, is also lacking. Therefore, further studies are needed to prove the hypothesis that DMF is a possible candidate as a DMARD for RA which would be effective, affordable, and have a low toxicity profile. The present study aimed to evaluate the effects and mechanism of DMF in an AIA model in rats.

\section{Materials and Methods}

\section{Experimental Animals}

All animal procedures and experimental protocols were approved by the Review Committee and Institutional Animal Ethics Committee [82/IAEC/528] of Post Graduate Institute of Medical Education and Research (PGIMER), Chandigarh, India. Young adult Wistar rats of either sex weighing 150 to $200 \mathrm{~g}$ were used for the present study. The experimental animals were housed in a room with a temperature of $23 \pm 2{ }^{\circ} \mathrm{C}$, relative humidity of $65^{\circ} \mathrm{C}$, and a 12- hour light / 12 -hour dark cycle. Standard pellet chow and tap water were provided to the animals. A period of 7 days was provided for acclimatization to laboratory conditions and among themselves. The present experimental work study was conducted in the central animal house facility in PGIMER, Chandigarh, India.

\section{Chemicals and drugs}

Complete Freund's adjuvant (CFA), Methotrexate (MTx), and DMF [97\%] were purchased from Sigma Chemicals, St. Louis, MO, USA. Dimethyl sulfoxide [DMSO] was purchased from Merck Specialities Private, Limited, Mumbai, India. ELISA kits for determining tumor necrosis factor $\alpha$ (TNF- $\alpha$ ) and interleukin 6 (IL-6) were purchased from RayBiotech, USA. All the other chemicals used in the present study were purchased in analytical grade from reputed companies.

\section{Grouping of Animals}

A total of 84 rats were used in the present study. The experimental animals were divided into fourteen groups as follows. 


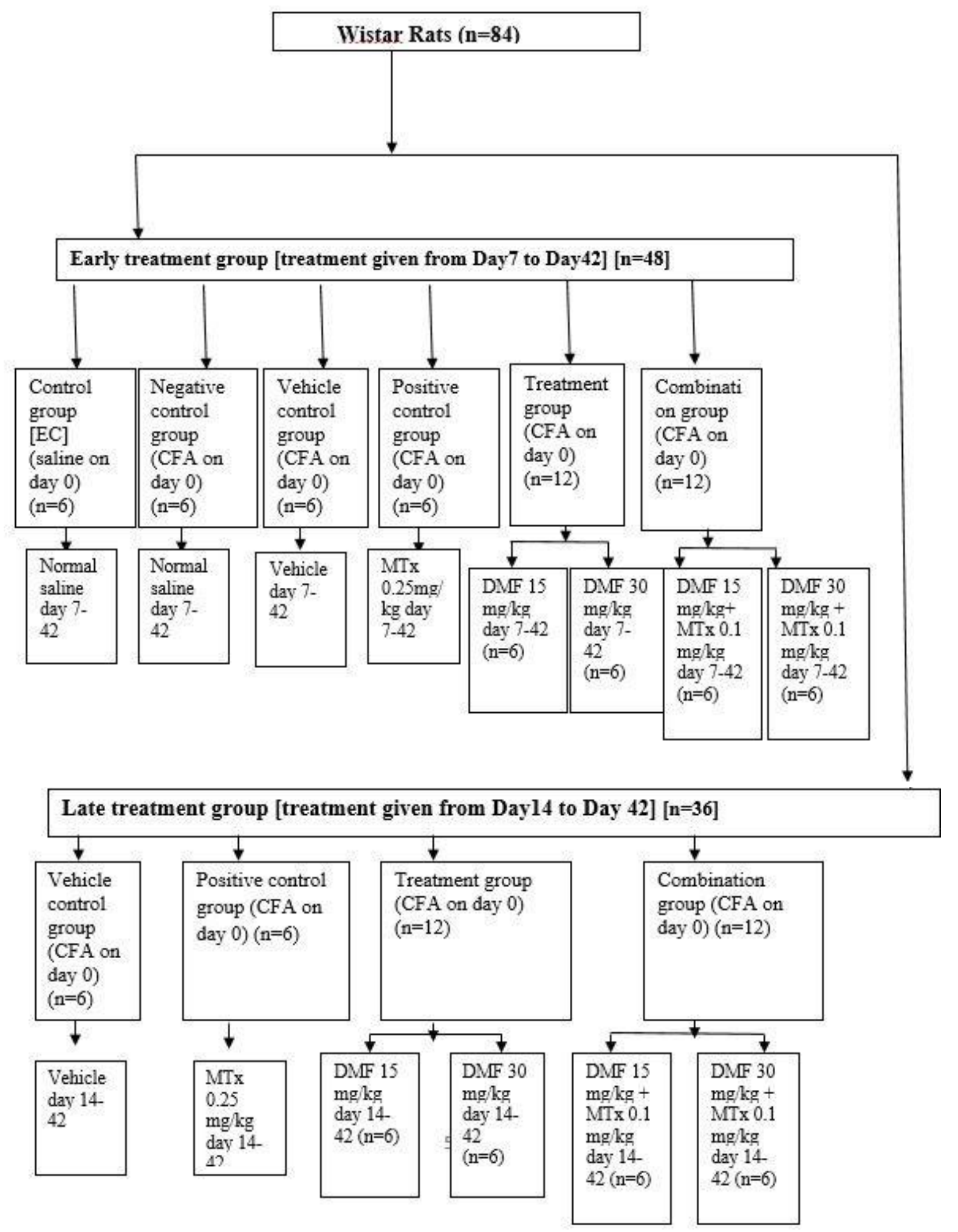

Adjuvant-Induced Arthritis (AIA) murine model

AIA was induced in a murine model according to the method of Morin C et al. [20]. Wistar rats were inoculated with complete Freund's adjuvant (CFA) [Each ml contained $1 \mathrm{mg}$ of heat-killed and dried mycobacterium tuberculosis (strain H37Ra, ATCC 25177), $0.85 \mathrm{ml}$ paraffin oil, and $0.15 \mathrm{ml}$ of mannide monooleate, purchased from Sigma Chemicals, St. Louis, MO, USA] to produce arthritis. On Day 0, rats were anaesthetized with ketamine/xylazine and $0.2 \mathrm{ml}$ of CFA was intradermally injected at the base of the tail followed by a booster dose 
of $0.1 \mathrm{ml}$ on Day 7. The control group was administered $0.1 \mathrm{ml}$ normal saline.

\section{Assessment of arthritis}

\section{Arthritis score [Macroscopic scoring]}

The development of arthritis was assessed in all animals every alternate day starting from Day 2. The hind limbs were examined for arthritic changes, such as swelling [increase in joint circumference], redness, or painful movement. A macroscopic scoring system was used to rate the severity of the arthritis that developed. A score ranging from 0-4 was applied to each hind limb [21, 22]. Then the scores of each limb were added [maximum score - 8]. [0 - no change, 1 - swelling and redness of one joint, 2 - two joints involved, 3 - more than two joints involved, 4 - severe arthritis of entire paws].

\section{Histopathological scoring of joint:}

On Day 42, the animals were euthanized by an overdose of ketamine/xylazine anaesthesia. For histopathological studies, the ankle joint of a hind limb [limb with maximum arthritic scoring] was dissected and fixed in $10 \%$ formalin for a minimum of 2 weeks. Then paraffin blocks and $2-\mu \mathrm{m}$ sections [3-4 sections per sample] were cut and stained with haematoxylin and eosin [H\&E] stain [23]. To determine inflammation in joint tissues, villi formation, synovial hyperplasia, and synovial vascularity, inflammatory tissue infiltrates and pannus formation, joint space exudation and narrowing of joint space, and bone and cartilage erosion were observed [24, 25]. A semi-quantitative histopathological grading was used [ 0 - normal/no change observed, 1 - minimal changes observed, 2 - moderate changes observed, 3 - severe changes observed].

\section{Blood sample collection}

On Day 42, $6 \mathrm{ml}$ of blood was collected by intracardiac puncture from each animal and was equally divided into 3 EDTA heparinized and non-heparinized vials. The heparinized and non-heparinized vials were centrifuged at $3000 \mathrm{rpm}$ at room temperature for 15 minutes to separate plasma and serum, respectively.

\section{Evaluation of oxidative stress parameters}

Fresh plasma was used to measure the following antioxidant parameters:

\section{Estimation of reduced glutathione level [GSH]}

Reduced glutathione [GSH] levels were measured by the method of Sedlak and Lindsay [26]. GSH was calculated using the extinction coefficient of $1.36 \times 10^{4}$ $\mathrm{mM}^{-1} \mathrm{~cm}^{-1}$ and expressed as $\mu \mathrm{mol} / \mathrm{L} / \mathrm{mg}$ of protein.

\section{Estimation of catalase level}

Catalase levels were measured by the method of Hadwan et al. [27]. Catalase enzymatic activity was expressed as $\mathrm{kU} / \mathrm{L} / \mathrm{mg}$ of protein.

\section{Estimation of superoxide dismutase [SOD] level}

Superoxide dismutase [SOD] levels were measured by the method of Kono et al. [28]. SOD enzymatic activity was expressed as IU/mg of protein. One unit of enzyme activity was expressed as one divided by the amount of homogenate needed to inhibit the reduction rate of NBT by fifty percent.

\section{Estimation of lipid peroxidation [MDA] level}

Lipid peroxidation [MDA] levels were measured by the method of Okhawa et al. [29]. MDA was calculated using the extinction coefficient of $1.53 \times 10^{5} \mathrm{mM}^{-1} \mathrm{~cm}^{-1}$ and expressed as $\mu \mathrm{mol} / \mathrm{L} / \mathrm{mg}$ of protein.

\section{Evaluation of anti-inflammatory and} immunomodulatory parameters

\section{Estimation of white blood cell [WBC] count}

White blood cells were estimated by the method of Bastidas et al. [30]. Briefly, $50 \mu 1$ of whole blood sample from an EDTA vial was diluted with $950 \mu$ of WBC diluting fluid to obtain a 1:20 dilution factor. Total leucocytes were counted manually using Neubauer's counting chamber under $10 \mathrm{X}$ magnification. TLC was expressed as no. of cells/ $\mu$ l of blood.

\section{Estimation of erythrocyte sedimentation rate [ESR]}

ESR was measured by the method of Gilmour et al. [31]. $1 \mathrm{ml}$ of whole blood was pipetted into a Wintrobe's tube and placed in a Wintrobe's stand [with no disturbance]. The level of RBC sediment was observed at $1 \mathrm{hr}$ for erythrocyte sedimentation rate. ESR was expressed as $\mathrm{mm} /$ hour.

\section{Estimation of serum TNF- $\alpha$ level and plasma IL-} 6 level

Cytokine levels were estimated by commercially available ELISA kits from RayBiotech. The kits quantitatively measured cytokine levels using sandwich ELISA. For cytokine estimation, samples of one group [6 samples] were pooled into 3 samples which were used for further assay [due to limited number of antibody-coated wells]. Estimation was performed following the kit protocol.

\section{Gene expression studies}

The mRNA expression of Nrf2, NFkB and $\beta$-actin (housekeeping gene) was done by using real-time polymerase chain reaction (RT-PCR) with SYBR green qPCR kit. For gene expression studies, phalangeal joints of the hind paw were used.

\section{Tissue preparation}

On Day 42, after sacrificing the animals, small joints (digits) of the hind paw (which had the highest macroscopic scoring) were dissected, skin scrapped, and stored in RNA at $-80^{\circ} \mathrm{C}$ until assay. Samples of one group (6 animals) were pooled into one sample (due to limited reagents) before processing. The bone samples were solidified with liquid nitrogen and then crushed into powder using a mortar and pestle. $100 \mathrm{mg}$ of powder was weighed and homogenized in $1 \mathrm{ml}$ of TRIzol reagent.

\section{RNA isolation}

Total RNA was isolated using the TRIzol reagent and according to the manufacturer's instructions.

Single-strand complementary DNA synthesis (cDNA synthesis) 
Single-strand complementary DNA (cDNA) was generated according to the protocol provided in the iScript cDNA Synthesis Kit with random hexamer primers.

\section{Real-time polymerase chain reaction (RT-PCR)}

Quantitative RT-PCR was run using SYBR green dye added to the template and primer in an appropriate thermocycler. The thermocycler had the capacity to illuminate each sample with a beam of light at a specified wavelength and detect fluorescence emitted by the excited fluorophore. The single-strand cDNA was used for amplification of genes with the following primers.

\section{$\beta$ actin: $\quad$ Forward: 5' AAG TCC CTC ACC CTC CCA AAAG 3' Reverse: 5' AAG CAA TGC TGT CAC CTT CCC 3' \\ Nrf2: $\quad$ Forward: 5' AGC AGG ACA AGG AGC AAG TT 3' Reverse: 5' CAG TGA GGG GAT TGA TGA GT 3' \\ NFkB: $\quad$ Forward: 5' TAC CCT CAG ACG CCA GAA GA 3' Reverse: 5' TCC TCT CTG TTT CGG TTG CT 3'}

$\beta$-actin, a housekeeping gene, was amplified as the reference or standard gene. Each sample was run in duplicate, and a control reaction was run without template for each gene. The PCR mixture was then run in the thermocycler according to the following cycling protocol:

$\begin{array}{ll}\text { Initial denaturation: } 95{ }^{\circ} \mathrm{C} \text { for } 600 \text { seconds } \\ \text { Denaturation: } & 95{ }^{\circ} \mathrm{C} \text { for } 10 \text { seconds } \\ \text { Annealing: } & 58.6{ }^{\circ} \mathrm{C}\left(\beta \text {-actin), } 59{ }^{\circ} \mathrm{C}(\mathrm{Nrf} 2), 49.0{ }^{\circ} \mathrm{C}(\mathrm{NF} \kappa \mathrm{B}) \text { for } 30 \text { seconds }\right. \\ \text { Elongation: } & 72{ }^{\circ} \mathrm{C} \text { for } 10 \text { seconds } \\ \text { Melting: } & 95{ }^{\circ} \mathrm{C} \text { for } 10 \text { seconds, } 65{ }^{\circ} \mathrm{C} \text { for } 60 \text { seconds, } 97{ }^{\circ} \mathrm{C} \text { for } 1 \text { second } \\ \text { Cooling: } & 37^{\circ} \mathrm{C} \text { for } 30 \text { seconds }\end{array}$

Initial denaturation: $95^{\circ} \mathrm{C}$ for 600 seconds

Denaturation: $\quad 95{ }^{\circ} \mathrm{C}$ for 10 seconds
$58.6^{\circ} \mathrm{C}(\beta$-actin $), 59^{\circ} \mathrm{C}(\mathrm{Nrf} 2), 49.0^{\circ} \mathrm{C}(\mathrm{NF} \kappa \mathrm{B})$ for 30 seconds
Melting:
$37^{\circ} \mathrm{C}$ for 30 seconds

inflammation of joints. There was a significant increase in arthritis score in the CFA control group compared with the saline control group [ $p$ value $<0.001]$. In both the early and the late MTx groups, a significant decrease was observed in the arthritis score compared with the CFA control group (Table 1). In all the combination groups (both early and late), there was also a significant decrease in the arthritis score compared to the CFA control group ( $p$ value $<0.001$ ). A greater decrease was seen in the early combination groups.

Effects of various treatments on histopathological scoring of ankle joint in AIA murine model

Histopathological scoring was done in a semiquantitative manner to determine relative inflammation of ankle joint tissue. The histopathological sections of various groups are shown in Figure 1. The mean histopathological scores of different groups are shown in Table 1. In the CFA control group, mild to moderate inflammatory changes were observed in villi formation, synovial hyperplasia and vascularity, and cartilage erosion; the mean score was 5.0 [ \pm 1.41$]$. The increase in mean histopathological score in the CFA control group was statistically significant $[p$ value $<0.001]$ when compared to the saline control group; however, the decrease in histopathological scoring in various treatment groups was not statistically significant compared to the CFA control group. 
Effects of various treatments on oxidative stress parameters in plasma in AIA murine model

In the CFA control group, there was a significant increase in the mean GSH, catalase, and MDA levels when compared with the saline control group (Table 2). Early and late administration of MTx significantly reduced the oxidative stress parameters ( $p$ value $<0.05)$. Early and late combinations of DMF $30 \mathrm{mg} / \mathrm{kg}$ and MTx were also able to reduce the oxidative stress (Table 2).

Effects of various treatments on total leucocyte count [TLC] and erythrocyte sedimentation rate [ESR] in AIA murine model

The mean TLC count was significantly increased in the CFA control group compared with the saline control group; however, the increase in ESR was not statistically significant, as shown in Table 3. The mean TLC count was significantly decreased in all the early treatment groups compared to the CFA control group. Among the late treatment groups, the mean TLC count was decreased in the late Mtx group and late DMF [30 mg/kg] and the MTx combination group. The decrease in ESR in all the

treatment groups were not statistically significant compared to the CFA control group.
Effects of various treatments on inflammatory cytokine levels in AIA murine model

In the CFA control group, there was a statistically significant $[p$ value $<0.001]$ increase in TNF $\alpha$ and IL-6 levels, as shown in Table 4. In all the treatment groups (both early and late), significant decreases were observed in mean serum TNF- $\alpha$ and IL-6 levels compared with the CFA control group. In the early treatment groups, the antiinflammatory effect was more prominent.

Effects of various treatments on relative expression of $\mathrm{Nrf} 2$ and $\mathrm{NF} \mathrm{B}$ genes in rat joint tissues

In the saline control group and vehicle control groups (early and late), the relative gene expression of $\mathrm{Nrf} 2$ and $\mathrm{NF} \kappa \mathrm{B}$ were less compared with that of the CFA control group, as shown in Table 5. In the early and late Mtx groups, expression of $\mathrm{NF \kappa B}$ was reduced compared with the CFA control group, as shown in Table 5. In all the DMF monotherapy (early and late) groups, Nrf2 expression was increased compared to the CFA control group and NFKB was decreased. In all the combination groups (early and late), Nrf2 and NFkB expression were decreased.

Table 1: Effect of various treatments on arthritis scoring (Macroscopic and histopathological scoring) of ankle joints in AIA model in rats.

\begin{tabular}{|c|c|c|c|c|}
\hline Groups & $\begin{array}{l}\text { Arthritis Score } \\
\qquad(\operatorname{Max}-16)\end{array}$ & $\begin{array}{c}p \text { value } \\
\text { (with respect to } \\
\text { ENC) }\end{array}$ & $\begin{array}{c}\text { Histopathological } \\
\text { Score } \\
(\mathrm{Max}-24)\end{array}$ & $\begin{array}{c}\text { p value } \\
\text { (with respect to ENC) }\end{array}$ \\
\hline Saline control group (EC) & $0.0( \pm 0)^{*}$ & $<0.001$ & $1.0( \pm 1.26)^{*}$ & $<0.001$ \\
\hline CFA control group (ENC) & $3.00( \pm 0)$ & & $5.0( \pm 1.41)$ & \\
\hline $\begin{array}{l}\text { Early DMSO control group } \\
\qquad(\text { EVC) }\end{array}$ & $2.83( \pm 0.41)$ & 1.000 & $4.2( \pm 2.23)$ & 1.000 \\
\hline Early Mtx group (EPC) & $1.33( \pm 0.52)^{*}$ & $<0.001$ & $2.8( \pm 1.17)$ & 0.175 \\
\hline $\begin{array}{c}\text { Early DMF } 15 \mathrm{mg} / \mathrm{Kg} \text { group } \\
\text { (ET1) }\end{array}$ & $2.00( \pm 0)^{*}$ & 0.016 & $3.7( \pm 1.15)$ & 1.000 \\
\hline $\begin{array}{l}\text { Early DMF } 30 \mathrm{mg} / \mathrm{Kg} \text { group } \\
\text { (ET2) }\end{array}$ & $2.00( \pm 0)^{*}$ & 0.016 & $2.7( \pm 1.15)$ & 0.539 \\
\hline $\begin{array}{l}\text { Early combination DMF } 15 \mathrm{mg} / \\
\text { Kg group (ECT1) }\end{array}$ & $1.50( \pm 0.55)^{*}$ & $<0.001$ & $2.5( \pm 0.58)$ & 0.128 \\
\hline $\begin{array}{l}\text { Early combination DMF } 30 \mathrm{mg} / \\
\text { Kg group (ECT2) }\end{array}$ & $1.33( \pm 0.52)^{*}$ & $<0.001$ & $2.6( \pm 0.55)$ & 0.101 \\
\hline $\begin{array}{l}\text { Late DMSO control group } \\
\qquad \text { (LVC) }\end{array}$ & $2.83( \pm 0.41)$ & 1.000 & $4.2( \pm 1.17)$ & 1.000 \\
\hline Late Mtx group (LPC) & $1.33( \pm 0.52)^{*}$ & $<0.001$ & $3.0( \pm 1.10)$ & 0.362 \\
\hline $\begin{array}{l}\text { Late DMF } 15 \mathrm{mg} / \mathrm{Kg} \text { group } \\
\text { (LT1) }\end{array}$ & $2.50( \pm 0.55)^{\#}$ & 1.000 & $3.8( \pm 0.75)$ & 1.000 \\
\hline $\begin{array}{c}\text { Late DMF } 30 \mathrm{mg} / \mathrm{Kg} \text { group } \\
\text { (LT2) }\end{array}$ & $2.00( \pm 0)^{*}$ & 0.016 & $3.4( \pm 0.55)$ & 1.000 \\
\hline
\end{tabular}




\begin{tabular}{|c|c|c|c|c|}
\hline Groups & $\begin{array}{l}\text { Arthritis Score } \\
\text { (Max - 16) }\end{array}$ & $\begin{array}{c}p \text { value } \\
\text { (with respect to } \\
\text { ENC) }\end{array}$ & $\begin{array}{c}\text { Histopathological } \\
\text { Score } \\
(\mathrm{Max}-24)\end{array}$ & $\begin{array}{c}\text { p value } \\
\text { (with respect to ENC) }\end{array}$ \\
\hline $\begin{array}{l}\text { Late combination DMF } 15 \mathrm{mg} / \\
\text { Kg group (LCT1) }\end{array}$ & $1.67( \pm 0.82)^{*}$ & $<0.001$ & $3.8( \pm 0.98)$ & 1.000 \\
\hline $\begin{array}{l}\text { Late combination DMF } 30 \mathrm{mg} / \\
\text { Kg group (LCT2) }\end{array}$ & $1.67( \pm 0.52)^{*}$ & $<0.001$ & $3.3( \pm 0.52)$ & 1.000 \\
\hline
\end{tabular}

Data are expressed as mean \pm SD. In each group $n=6$ animals. One way ANOVA followed by Bonferroni post-hoc analysis. * $-\mathrm{p}-$ $<0.05$ compared to CFA control group. \# - p - <0.05 compared to early Mtx group

Table 2: Effect of various treatments on oxidative stress parameters in plasma in AIA model in rats.

\begin{tabular}{|c|c|c|c|c|}
\hline Groups & $\begin{array}{c}\text { GSH } \\
(\mu \mathrm{mol} / \mathrm{L} / \mathrm{mg} \text { of protein })\end{array}$ & $\begin{array}{c}\text { Catalase } \\
\text { (kU/L/mg of protein) }\end{array}$ & $\begin{array}{c}\text { SOD } \\
\text { (IU/mg of protein) }\end{array}$ & $\begin{array}{c}\text { MDA } \\
(\mu \mathrm{mol} / \mathrm{L} / \mathrm{mg} \text { of protein) }\end{array}$ \\
\hline $\mathrm{EC}$ & $5.7( \pm 1.03)$ & $27.4( \pm 18.01)$ & $7.1( \pm 1.41)$ & $20.2( \pm 3.98)$ \\
\hline ENC & $37.0( \pm 2.17)$ & $143.3( \pm 11.33)$ & $0.8( \pm 0.34)$ & $62.9( \pm 13.41)$ \\
\hline EVC & $39.6( \pm 4.89)$ & $129.9( \pm 44.87)$ & $1.1( \pm 0.38)$ & $72.9( \pm 17.33)$ \\
\hline EPC & $18.0( \pm 6.03)^{*}$ & $50.1( \pm 14.18)^{*}$ & $6.5( \pm 1.33)^{*}$ & $34.3( \pm 6.22)^{*}$ \\
\hline ET1 & $40.6( \pm 9.35)$ & $102.7( \pm 24.42)$ & $2.0( \pm 0.45)$ & $72.2( \pm 14.41)$ \\
\hline ET2 & $30.4( \pm 9.36)$ & $77.2( \pm 29.81)^{*}$ & $2.5( \pm 0.53)^{\#}$ & $62.6( \pm 17.55)$ \\
\hline ECT1 & $20.1( \pm 6.19)^{*}$ & $68.5( \pm 16.93)^{*}$ & $5.2( \pm 1.05)^{*}$ & $61.9( \pm 14.68)$ \\
\hline ECT2 & $11.7( \pm 1.07)^{*}$ & $50.6( \pm 13.05)^{*}$ & $5.7( \pm 1.28)^{*}$ & $44.4( \pm 10.47)$ \\
\hline LVC & $36.6( \pm 5.97)$ & $100.1( \pm 23.02)$ & $1.1( \pm 0.31)$ & $70.6( \pm 8.34)$ \\
\hline LPC & $19.3( \pm 4.92)^{*}$ & $28.4( \pm 4.33)^{*}$ & $4.3( \pm 1.10)^{\text {*\# }}$ & $43.8( \pm 12.09)$ \\
\hline LT1 & $38.1( \pm 10.77)^{\#}$ & $153.6( \pm 27.54)^{\#}$ & $1.4( \pm 0.21)^{\#}$ & $74.3( \pm 9.37)^{\#}$ \\
\hline LT2 & $19.8( \pm 7.45)^{*}$ & $92.9( \pm 21.46)^{*}$ & $2.4( \pm 0.69)^{\#}$ & $63.9( \pm 15.72)^{\#}$ \\
\hline LCT1 & $15.7( \pm 4.66)^{*}$ & $89.6( \pm 8.51)^{*}$ & $2.2( \pm 0.54)^{\#}$ & $68.3( \pm 9.03)^{\#}$ \\
\hline LCT2 & $15.2( \pm 4.05)^{*}$ & $66.3( \pm 14.32)^{*}$ & $3.9( \pm 1.23)^{* \#}$ & $51.7( \pm 10.09)$ \\
\hline
\end{tabular}

Data are expressed as mean \pm SD. In each group $n=6$ animals. One way ANOVA followed by Bonferroni post-hoc analysis. * $-\mathrm{p}-$ $<0.05$ compared to CFA control group. \# - p - <0.05 compared to early Mtx group. EC - saline control group, ENC - CFA control group, EVC - early DMSO control group, EPC - early Mtx group, ET1 - early DMF 15 mg/ Kg group, ET2 - early DMF $30 \mathrm{mg} / \mathrm{Kg}$ group, ECT1 - early combination DMF $15 \mathrm{mg} / \mathrm{Kg}$ group, ECT2 - early DMF $30 \mathrm{mg} / \mathrm{Kg}$ group, LVC - late DMSO control group, LPC - late Mtx group, LT1 - late DMF 15 mg/ Kg group, LT2 - late DMF 30 mg/ Kg group, LCT1 - late combination DMF 15 mg/ $\mathrm{Kg}$ group, LCT2 - late DMF $30 \mathrm{mg} / \mathrm{Kg}$ group. 
Table 3: Effect of various treatments on Total Leucocyte Count (TLC) and ESR level in AIA model in rats.

\begin{tabular}{|c|c|c|c|c|}
\hline Groups & $\begin{array}{c}\text { TLC } \\
(\text { no. of cells } / \mu L)\end{array}$ & $\begin{array}{c}p \text { value } \\
\text { (with respect to } \\
\text { ENC) }\end{array}$ & $\begin{array}{c}\text { ESR } \\
(\mathrm{mm} / \mathrm{hour})\end{array}$ & $\begin{array}{c}p \text { value } \\
\text { (with respect to } \\
\text { ENC) }\end{array}$ \\
\hline Saline control group (EC) & $5800.0( \pm 413.52)^{*}$ & $<0.001$ & $0.1( \pm 0.10)$ & 1.000 \\
\hline CFA control group (ENC) & $10041.7( \pm 1954.08)$ & & $0.3( \pm 0.26)$ & \\
\hline $\begin{array}{l}\text { Early DMSO control group } \\
\qquad(\mathrm{EVC})\end{array}$ & $11791.7( \pm 1498.81)$ & 1.000 & $0.3( \pm 0.25)$ & 1.000 \\
\hline Early Mtx group (EPC) & $5741.7( \pm 678.54)^{*}$ & $<0.001$ & $0.2( \pm 0.26)$ & 1.000 \\
\hline $\begin{array}{c}\text { Early DMF } 15 \text { mg/ Kg group } \\
\text { (ET1) }\end{array}$ & $5708.3( \pm 889.05)^{*}$ & $<0.001$ & $0.4( \pm 0.16)$ & 1.000 \\
\hline $\begin{array}{c}\text { Early DMF } 30 \mathrm{mg} / \mathrm{Kg} \text { group } \\
\text { (ET2) }\end{array}$ & $5266.7( \pm 1548.44)^{*}$ & $<0.001$ & $0.3( \pm 0.20)$ & 1.000 \\
\hline $\begin{array}{c}\text { Early combination DMF } 15 \\
\text { mg/ Kg group (ECT1) }\end{array}$ & $4933.3( \pm 1046.26)^{*}$ & $<0.001$ & $0.1( \pm 0.19)$ & 1.000 \\
\hline $\begin{array}{c}\text { Early combination DMF } 30 \\
\text { mg/ Kg group (ECT2) }\end{array}$ & $4591.7( \pm 707.40)^{*}$ & $<0.001$ & $0.1( \pm 0.13)$ & 1.000 \\
\hline $\begin{array}{l}\text { Late DMSO control group } \\
\qquad(\mathrm{LVC})\end{array}$ & $11816.7( \pm 2114.16)$ & 1.000 & $0.3( \pm 0.20)$ & 1.000 \\
\hline Late Mtx group (LPC) & $4766.7( \pm 450.19)^{*}$ & $<0.001$ & $0.1( \pm 0.09)$ & 1.000 \\
\hline $\begin{array}{l}\text { Late DMF } 15 \mathrm{mg} / \mathrm{Kg} \text { group } \\
\text { (LT1) }\end{array}$ & $10125.0( \pm 2625.60)^{\#}$ & 1.000 & $0.2( \pm 0.23)$ & 1.000 \\
\hline $\begin{array}{c}\text { Late DMF } 30 \mathrm{mg} / \mathrm{Kg} \text { group } \\
\text { (LT2) }\end{array}$ & $7725.0( \pm 1620.73)$ & 0.583 & $0.2( \pm 0.18)$ & 1.000 \\
\hline $\begin{array}{l}\text { Late combination DMF } 15 \mathrm{mg} / \\
\qquad \mathrm{Kg} \text { group (LCT1) }\end{array}$ & $7833.3( \pm 1037.14)$ & 0.837 & $0.2( \pm 0.19)$ & 1.000 \\
\hline $\begin{array}{l}\text { Late combination DMF } 30 \mathrm{mg} / \\
\qquad \mathrm{Kg} \text { group (LCT2) }\end{array}$ & $6408.3( \pm 1337.32)^{*}$ & 0.003 & $0.2( \pm 0.19)$ & 1.000 \\
\hline
\end{tabular}

Data are expressed as mean \pm SD. In each group $n=6$ animals. One way ANOVA followed by Bonferroni post-hoc analysis. * $-\mathrm{p}-$ $<0.05$ compared to CFA control group. \# - p - <0.05 compared to early Mtx group.

Table 4: Effect of various treatments on inflammatory cytokine levels in AIA model in rats.

\begin{tabular}{ccc}
\hline Groups & $\begin{array}{c}\text { Serum TNF-a } \\
(\mathbf{p g} / \mathbf{m l} / \mathbf{m g} \text { of protein) }\end{array}$ & $\begin{array}{c}\text { Plasma IL-6 } \\
(\mathbf{p g} / \mathbf{m l} / \mathbf{m g} \text { of protein) }\end{array}$ \\
\hline Saline control group (EC) & $129.9( \pm 50.29)^{*}$ & $48.7( \pm 3.21)^{*}$ \\
CFA control group (ENC) & $402.8( \pm 40.80)$ & $133.1( \pm 5.09)$ \\
Early DMSO control group (EVC) & $392.8( \pm 49.00)$ & $100.6( \pm 8.69)$ \\
Early Mtx group (EPC) & $136.1( \pm 25.72)^{*}$ & $50.1( \pm 2.70)^{*}$ \\
Early DMF 15 mg/ Kg group (ET1) & $195.3( \pm 61.24)^{*}$ & $114.2( \pm 20.72)^{\#}$ \\
Early DMF 30 mg/ Kg group (ET2) & $147.2( \pm 25.51)^{*}$ & $86.5( \pm 16.32)^{* \#}$
\end{tabular}




\begin{tabular}{ccc}
\hline Groups & $\begin{array}{c}\text { Serum TNF- } \\
(\mathbf{p g} / \mathbf{m l} / \mathbf{m g} \text { of protein) }\end{array}$ & $\begin{array}{c}\text { Plasma IL-6 } \\
(\mathbf{p g} / \mathbf{m l} / \mathbf{m g} \text { of protein) }\end{array}$ \\
\hline Early combination DMF 30 mg/ Kg group (ECT2) & $137.8( \pm 9.09)^{*}$ & $59.1( \pm 10.11)^{*}$ \\
Late DMSO control group (LVC) & $444.8( \pm 96.35)$ & $120.7( \pm 12.05)$ \\
Late Mtx group (LPC) & $123.5( \pm 14.62)^{*}$ & $54.5( \pm 9.58)^{*}$ \\
Late DMF 15 mg/ Kg group (LT1) & $218.4( \pm 43.44)^{*}$ & $88.3( \pm 17.34)^{* \#}$ \\
Late DMF 30 mg/ Kg group (LT2) & $166.2( \pm 10.98)^{*}$ & $81.4( \pm 6.84)^{*}$ \\
Late combination DMF 15 mg/ Kg group (LCT1) & $191.7( \pm 26.60)^{*}$ & $56.7( \pm 8.19)^{*}$ \\
Late combination DMF 30 mg/ Kg group (LCT2) & $185.4( \pm 39.60)^{*}$ & $52.2( \pm 3.57)^{*}$
\end{tabular}

Data are expressed as mean \pm SD. In each group $n=6$ animals. One way ANOVA followed by Bonferroni post-hoc analysis. * - p $<0.05$ compared to CFA control group. \# - p - <0.05 compared to early Mtx group.

Table 5: Effect of various treatments on relative gene expression in rat joint tissues in AIA model in rats.

\begin{tabular}{|c|c|c|}
\hline \multirow{2}{*}{ Groups } & \multicolumn{2}{|c|}{ Relative gene expression (fold change) } \\
\hline & Nrf2 & NFкB \\
\hline Saline control group (EC) & $0.14(-)$ & $0.53(-)$ \\
\hline Early DMSO control group (EVC) & $0.05(-)$ & $1.14(+)$ \\
\hline Early Mtx group (EPC) & $0.07(-)$ & $0.58(-)$ \\
\hline Early DMF 15 mg/ Kg group (ET1) & $1.23(+)$ & $0.30(-)$ \\
\hline Early DMF 30 mg/ Kg group (ET2) & $1.05(+)$ & $0.46(-)$ \\
\hline Early combination DMF $15 \mathrm{mg} / \mathrm{Kg}$ group (ECT1) & $0.31(-)$ & $0.45(-)$ \\
\hline Early combination DMF 30 mg/ Kg group (ECT2) & $0.32(-)$ & $0.50(-)$ \\
\hline Late DMSO control group (LVC) & $0.03(-)$ & $1.35(+)$ \\
\hline Late Mtx group (LPC) & $0.09(-)$ & $0.44(-)$ \\
\hline Late DMF 15 mg/ Kg group (LT1) & $1.61(+)$ & $0.09(-)$ \\
\hline Late DMF 30 mg/ Kg group (LT2) & $1.11(+)$ & $0.10(-)$ \\
\hline Late combination DMF 15 mg/ Kg group (LCT1) & $0.27(-)$ & $0.19(-)$ \\
\hline Late combination DMF 30 mg/ Kg group (LCT2) & $0.22(-)$ & $0.27(-)$ \\
\hline
\end{tabular}

Data are expressed as fold change compared to CFA control group. Descriptive analysis (frequency table). $<1$-fold change considered (-) indicating reduced expression of target genes ( $\mathrm{Nrf} 2$ and $\mathrm{NF \kappa B}$ ) to comparator, $\geq 1$-fold change considered $(+)$ indicating increased expression of target genes ( $\mathrm{Nrf2}$ and $\mathrm{NF \kappa B})$ to comparator. 
a) Saline control

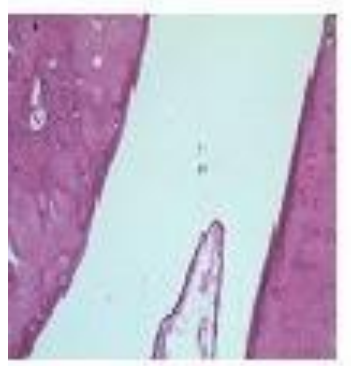

e) Early DMF $15 \mathrm{mg}$

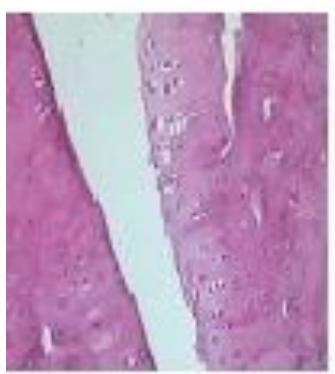

i) Late rehile control

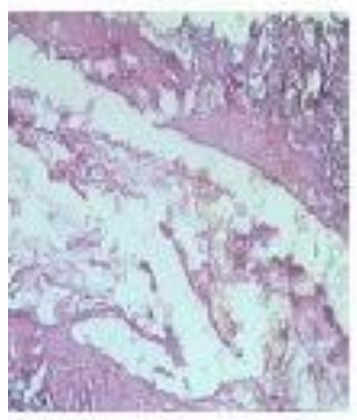

\section{b) CFA control}

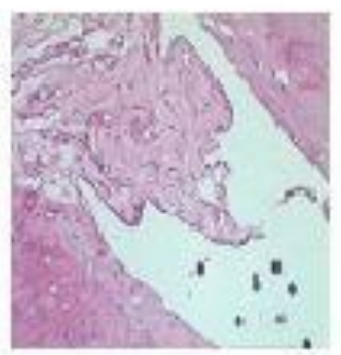

c) Early rehicle control

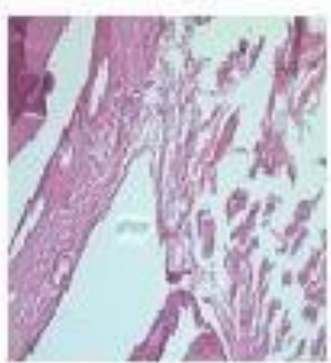

d) Early Mtx

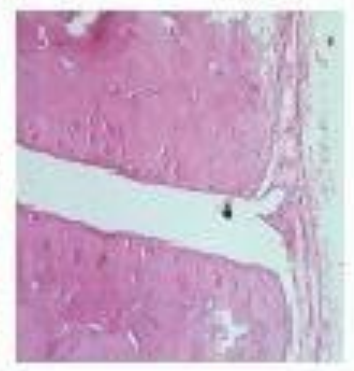

f) Eark DMF $30 \mathrm{mg}$

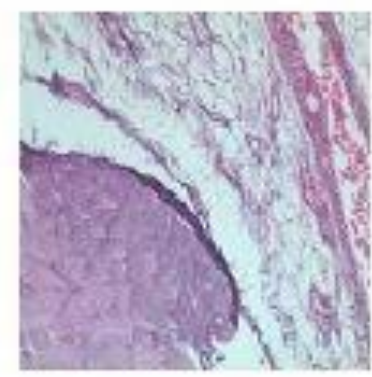

j) Late Mtx

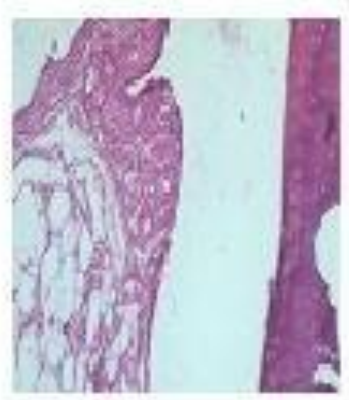

g) Early DMF $15 \mathrm{mg}-\mathrm{Mtx}$

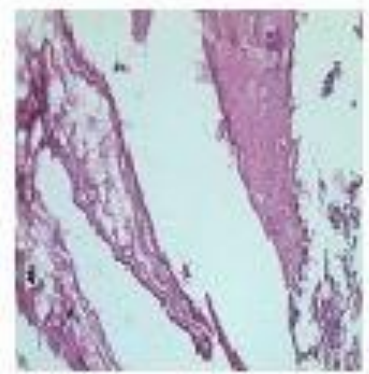

k) Late DMF $15 \mathrm{mg}$

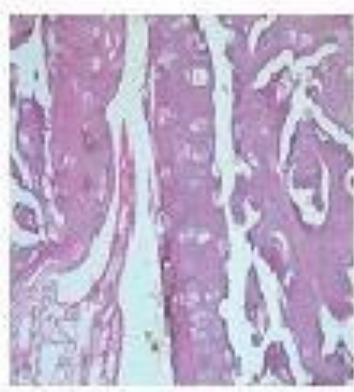

\section{h) Early DMF $30 \mathrm{mg}+\mathrm{Mtx}$}

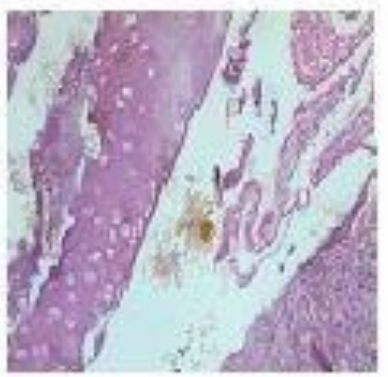

1) Late DMF $30 \mathrm{mg}$

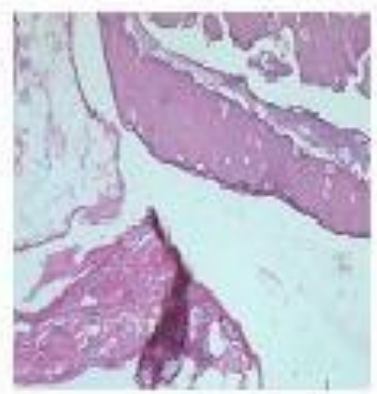

m) Late DMF $15 \mathrm{mg}+\mathrm{Mt} \mathbf{x}$

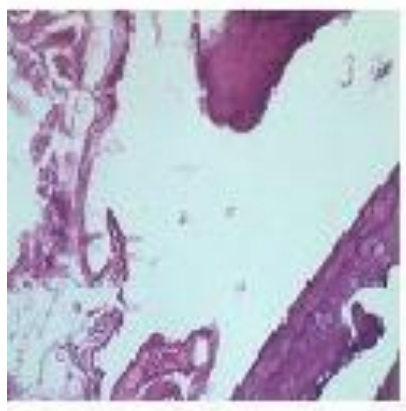

n) Late DMF $30 \mathrm{mg}+\mathbf{M t x}$

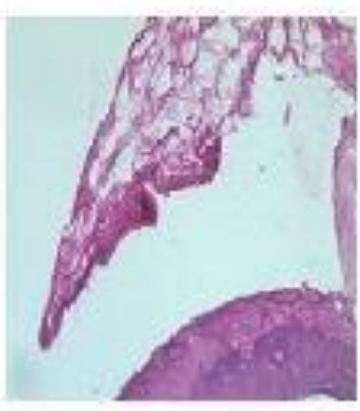

Figure 1: Microscopic [40x] examination of rat ankle joints showing joint morphology in the various treatment groups in murine model of AIA. a] Saline control group showing normal histology of ankle joint; b] CFA control group showing synovitis and cartilage erosion; c] \& i] showing inflammatory signs similar to CFA control group; d] \& j] showing fewer inflammatory signs of synovium and erosion of cartilage than CFA control group; e], f], g], h], k], l], m], \& n] Various treatment groups of DMF monotherapy and combination therapy showing less inflammation of synovitis and less cartilage erosion than CFA control group. 


\section{Discussion}

In the present study, DMF alone demonstrated some anti-inflammatory effects by decreasing arthritis and histopathological scorings compared with the CFA control group in both the early and late treatment groups, but those decreases was not statistically significant. DMF alone showed a decrease in all experimental parameters, but it was not statistically significant when compared with the CFA group. Significant effects were observed when DMF was combined with Mtx. In all the above-mentioned parameters, the best response was observed in the early combination therapy of DMF $30 \mathrm{mg} / \mathrm{kg}$ and Mtx 0.1 $\mathrm{mg} / \mathrm{kg}$, which was comparable with the response of the Mtx $0.25 \mathrm{mg} / \mathrm{kg}$ group.

Throughout the years, animal studies have been conducted to understand the etiopathogenesis of RA and to screen for various DMARDs. The AIA model is one of the oldest and most common animal models used for experimental studies regarding RA. In the CFA-induced AIA model, inflammation and swelling of paw joints appeared 10-12 days after adjuvant injection [20, 32]. In the current study, the maximum inflammation of joints and increase in joint circumference were seen 10-14 days after the first dose of CFA inoculation. This result is at par with previous studies. The decrease in arthritis scoring in various DMF treatment groups [monotherapy or combination therapy] compared with the CFA control group indicates the degree of protection provided each group from developing severe arthritis. Combination therapy groups demonstrated better responses than the DMF monotherapy groups.

In animal models of RA [CFA-induced arthritis], radiological and histopathological examinations of diseased joints show various signs of inflammation like synovitis [synovial hyperplasia, increased vascularity, villi formation], soft tissue inflammation [inflammatory cell infiltrate and pannus formation], narrowing of joint space and exudation in joint space, and cartilage and bone erosion. In the present study, $H \& E$ stained slides were examined under a lighted microscope with 40X magnification to observe the histological changes in rat ankle joints of the hind paw. A statistically significant increase in histological score was observed in the CFA control group compared with the saline control group which indicates the successful development of the model, and it was in accordance with the macroscopic scoring. In the various treatment groups of DMF monotherapy and combination therapy of DMF and Mtx, a decrease in histological score might indicate the degree of protection from inflammatory changes in ankle joints provided by each group.

A number of studies have indicated the role of excess reactive oxygen species (ROS) production coupled with reduced activity of endogenous antioxidants on the development of RA [20, 33]. Under physiological conditions, the harmful effects of ROS are nullified by endogenous antioxidants. Oxidative stress, a condition in which there is an imbalance of the ratio of oxidants and endogenous antioxidants, leads to various chronic and degenerative diseases, including RA. Studies have reported that the focal loss of cartilage occurring in RA might be due to reactive oxygen and nitrogen intermediates [20, 33]. In this study, reduced GSH, catalase, and MDA levels were significantly increased in the CFA control group compared with the saline control group, while levels of SOD were significantly decreased in the CFA control group. The amount of increase in levels of SOD and decrease in levels of GSH, catalase, and MDA compared with the CFA control group represent the amount of protection provided by the treatment against oxidative stress.

RA is a chronic inflammatory condition with inflammation of the joints, leading to elevated TLC counts. In the present study, a significant increase in TLC count was observed in the CFA control group compared with the saline control group $[p$ value $<0.001]$, suggesting increased inflammation in the CFA control group. The decrease in TLC count in each treatment group demonstrated the antiinflammatory effects provided by the treatment. Erythrocyte sedimentation rate [ESR] is another marker of inflammation and is often observed in both clinical and experimental settings for RA [32, 20, 34]. ESR is a nonspecific marker of inflammation that is elevated in multiple disease conditions like RA, ankylosing spondylosis, polymyalgia rheumatica, psoriatic arthritis, systemic sclerosis, and so on. In the present study, there was no significant change in ESR among the various groups, which can be explained by the non-specific nature of ESR as a marker of inflammation [32, 20].

TNF- $\alpha$ and IL- 6 are pro-inflammatory cytokines that have been associated with inflammation of joints and oxidative stress in RA [35]. In the current study, a significant increase in serum TNF- $\alpha$ and IL-6 levels was observed compared with the saline control group. The decrease in cytokine levels in different treatment groups indicates the level of anti-inflammatory and immunomodulatory effects of that treatment.

Gene expression studies were conducted with the purpose of differentiating between diseased conditions and normal conditions at the molecular level. Oxidative stress and pro-inflammatory cytokines play a significant role in the etiopathogenesis of RA; hence, genes which encode proteins in the above-mentioned pathways are affected. The Nrf2 gene is responsible for increased expression of antioxidant defense enzymes like catalase and SOD under oxidative stress. The NFKB gene is considered to be responsible for inflammatory factors such as proinflammatory cytokines (like TNF- $\alpha$, IL-6, IL-1 $\beta$, IL-8, IL12, IFN- $\gamma$ ), ROS, prostaglandins, and matrix metalloproteinase.

In real-time quantitative PCR (qPCR), each sample must be normalized against a housekeeping gene. In the present study, $\beta$-actin was considered as the internal standard for normalization of each sample. Nrf2 regulates the expression of various proteins and other genes through its promoter sequence antioxidant-response element (ARE). Oxidative stress leads to activation of Nrf2 (by dissociation from Keap 1 protein), leading to activation of 
an ARE promoter region, which in turn leads to upregulation of various antioxidants, phase II detoxification, and anti-inflammatory genes. Some of the important antioxidant genes upregulated by $\mathrm{Nrf} 2$ are $\mathrm{NAD}(\mathrm{P}) \mathrm{H}$ quinone reductase (NQO1), glutathione $\mathrm{S}$ transferase (GST), $\gamma$-glutamylcysteine synthetase, uridine diphosphate-glucuronosyltransferases, and epoxide hydrolase which help in increased cell survival by upregulating the cell defense system $[36,37]$. In the present study, the expression of Nrf2 in the saline control group was less compared with the CFA control group. This can be explained by increased oxidative stress in the CFA control group which led to the upregulation of Nrf2. In the early and late vehicle control groups, Nrf2 expression was marginally decreased compared to the CFA control group, indicating an insignificant role of the vehicle (DMSO 30\%) in the Nrf2 pathway. In early and late Mtx groups, no appreciable change in Nrf2 expression was observed compared with the CFA control group. This decreased expression of Nrf2 in the Mtx group might be explained by the fact that Mtx acts as an anti-inflammatory agent by downregulating $\mathrm{NF} \kappa \mathrm{B}$ through a pathway separate from Nrf2 (through adenosine signalling pathway) [38]. In early and late DMF monotherapy groups, increased Nrf2 expression was observed, suggesting that DMF acted as an activator of Nrf2, leading to the antioxidant effect observed in the respective groups. Previous experimental studies also support the role of DMF in activation of Nrf2. In early and late combination therapy of DMF and Mtx, decreased expression of $\mathrm{Nrf} 2$ was observed compared with the CFA control group, which might be explained by the action of Mtx through a pathway other than Nrf2.

In the present study, NFKB expression was less in the saline control group than in the CFA control group. This upregulation of $\mathrm{NF} \kappa \mathrm{B}$ in the CFA control group was in accordance with the findings of increased inflammation and elevated TLC and cytokine levels in the CFA control group. In early and late vehicle control groups, $\mathrm{NF \kappa B}$ expression was increased compared with the CFA control group, indicating an insignificant role of the vehicle (DMSO 30\%) in downregulating the NFkB pathway. In early and late Mtx groups, decreases in NFאB expression were observed compared with the CFA control group. This decreased expression of $\mathrm{NF} \kappa \mathrm{B}$ in the Mtx groups might be explained by the downregulation of NFKB through the adenosine signalling pathway mediated by adenosine receptor A3 (ADORA3) [38]. In early and late DMF monotherapy groups, decreased expression of NFKB was observed, suggesting that DMF played a role in inhibiting the NFKB pathway, leading to anti-inflammatory and immunomodulatory effects observed in the respective groups. This finding could be supported by earlier experimental studies which depict the role of DMF in inhibiting the $\mathrm{NF} \kappa \mathrm{B}$ pathway. In early and late combination therapy of DMF and Mtx, decreased NF $\kappa$ B expression was observed compared with the CFA control group, which might be explained by the action of both Mtx and DMF.

The above observations indicate DMF might be a candidate as a DMARD, owing to its antioxidant, anti- inflammatory, and immunomodulatory effects. The above observations also indicate the combination of DMF with low-dose Mtx might lead to a reduction in the dose-related toxicity of Mtx.

\section{Merits of the Study}

At present, several disease modifying antirheumatoid drugs [DMARDs] are available for the treatment of RA, but all of them have limitations in terms of adverse effects or cost effectiveness. DMF is an herbal product with immunomodulatory effects and demonstrated diseasemodifying antirheumatoid activity in the present study in a murine model of CFA-induced arthritis. Fewer side effects occur with DMF compared with other DMARDs, and DMF also costs less. Thus, DMF can be used as a DMARD in the future.

\section{Limitations of the Study}

The extrapolation of the results of any animal study into clinical practice is not always the same. In an animal model, it is not always possible to produce the same disease pathology in the animals. In the present study, we were not able to perform radiological assessments (X-rays) of the joints or pain assessment in the animals.

\section{Conclusion}

The present study was conducted with the aim of exploring the effects of DMF in RA and to explore its possible mechanisms of action through which it might exert its effect on RA. The study also explored the possibility of combining DMF with Mtx for the management of RA.

DMF demonstrated anti-inflammatory effects by decreasing arthritis and histopathological scores compared with the CFA control group, though the difference was not statistically significant. DMF also exhibited antioxidant effects by increasing plasma SOD levels compared with the CFA control group. The anti-inflammatory and immunomodulatory properties of DMF were observed by decreases in TLC count, serum TNF- $\alpha$ levels, and plasma IL-6 levels. In all the above-mentioned parameters, the best response was observed in the early combination therapy of DMF $30 \mathrm{mg} / \mathrm{kg}$ and Mtx $[0.1 \mathrm{mg} / \mathrm{kg}]$, which was comparable with the response of the Mtx $[0.25 \mathrm{mg} / \mathrm{kg}]$ group.

\section{Acknowledgments}

Each individual named as an author meets the journal's criteria for authorship.

\section{Funding}

No specific funding was received from any bodies in the public, commercial, or not-for-profit sectors to carry out the work described in this article.

\section{Conflict of interest}

The authors have declared no conflicts of interest. 


\section{References}

1. Scott DL, Wolfe F, Huizinga TW. Rheumatoid arthritis. Lancet 2010; 376(9746):1094-08. doi: 10.1016/S0140-6736(10)60826-4.

2. Mahran, SA, Khedr, TM, Mohammed, EM, ELHakeim EMH. Medication adherence to diseasemodifying anti-rheumatic drugs among patients with rheumatoid arthritis at Assiut University Hospital, Egypt. Egypt Rheumatol Rehabil 2020; 47(1):3. doi.org/10.1186/s43166-020-00005-6

3. McInnes B and Schett G. The pathogenesis of rheumatoid arthritis. N Engl J Med 2011; 365(23): 2205-19. doi: 10.1056/NEJMra1004965.

4. Scublinsky D, Gonzalez C. Quantifying Disease in Challenging Conditions: Incidence and Prevalence of RheumatoidArthritis. J Rheumatol 2016; 43(7):1263-64. doi:10.3899/jrheum.160522

5. Handa R. Rheumatology in India-quo vadis? Nat Rev Rheumatol 2015; 11(3):183-88. doi: 10.1038/nrrheum.2014.182.

6. Choudhary N, Bhatt LK, Prabhavalkar KS. Experimental animal models for rheumatoid arthritis. Immunopharmacol Immunotoxicol 2018; 40(3):193-200. 10.1080/08923973.2018.1434793.

7. Singh JA, Saag KG, Bridges SL, Akl EA, Bannuru RR, Sullivan MC. et al. 2015 American College of Rheumatology guideline for the treatment of rheumatoid arthritis. Arthritis Rheumatol 2016; 68(1):1-26. doi: 10.1002/art.39480.

8. Kourbeti IS, Ziakas PD, Mylonakis E. Biologic Therapies in Rheumatoid Arthritis and the Risk of Opportunistic Infections: A Meta-analysis. Clin

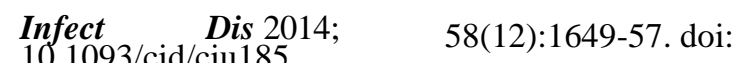

9. Singh JA, Wells GA, Christensen R, Tanjong Ghogomu E, Maxwell LJ, Macdonald JK. et al. Adverse effects of biologics: a network meta. analysis and Cochrane overview. Cochrane Database Syst Rev 2011; 2011(2): CD008794. doi: 10.1002/14651858.CD008794.pub2.

10. Chadha S, Behl T, Kumar A, Khullar G, Arora S. Role of Nrf2 in rheumatoid arthritis. Curr Res Transl Med 2020; 68(4):171-81. doi: 10.1016/j.retram.2020.05.002.
11. Liu T, Zhang L, Joo D, Shao-Cong S. NF- $\kappa$ B signaling in inflammation. Signal Transduct Target Ther 2017; 2:e17023; doi: 10.1038/sigtrans.2017.23.

12. Wardyn JD, Ponsford AH, Sanderson CM. Dissecting molecular cross-talk between Nrf2 and NF- $\kappa$ B response pathways. Biochem Soc Trans 2015; 43(4):621-26. doi: 10.1042/BST20150014.

13. Seidel P, Roth M. Anti-inflammatory dimethyl fumarate: a potential new therapy for asthma? Mediators Inflamm 2013; 2013:875403. doi: $10.1155 / 2013 / 875403$.

14. Oh CJ, Kim JY, Choi YK, Kim HJ, Jeong JY, Bae KH. et al. Dimethyl fumarate attenuates renal fibrosis via NF-E2-related factor 2 mediated inhibition of transforming growth factor- $\beta / \mathrm{Smad}$ signaling. PLoS One 2012; 7(10):e45870. doi: 10.1371/journal.pone.0045870.

15. Zhao X, Sun G, Zhang J, Ting SM, Gonzales N, Aronowski J. Dimethyl Fumarate Protects Brain From Damage Produced by Intracerebral Hemorrhage by Mechanism Involving Nrf2. Stroke 2015; 46(7): 1923-28. doi: 10.1161/STROKEAHA.115.009398.

16. Gill AJ, Kolson DL. Dimethyl fumarate modulation of immune and antioxidant responses: application to HIV therapy. Crit Rev Immunol 2013; 33:(4)307-59. doi: 10.1615/critrevimmunol.2013007247.

17. Fox RJ, Kita M, Cohan SL, Henson LJ, Zambrano J, Scannevin RH. et al. BG-12 (dimethyl fumarate): a review of mechanism of action, efficacy, and safety. Curr Med Res Opin 2014; 30(2):251-62. doi: 10.1185/03007995.2013.849236.

18. Roshan Lal, Jatinder Dhaliwal, Navneet Dhaliwal, Ravinder Naik Dharavath, Kanwaljit Chopra. Activation of the Nrf2/HO-1 signaling pathway by dimethyl fumarate ameliorates complete Freund's adjuvant-induced arthritis in rats. Eur J Pharmacol 2021; 899:174044. doi: 10.1016/j.ejphar.2021.174044. Epub 2021

19. Efficacy and Safety Study of BG00012 with Methotrexate in Patients with Active Rheumatoid Arthritis. [https://clinicaltrials.gov/ct2/show/NCT00810836? term=Efficacy+and+Safety+Study+of+BG00012+ 
With + Methotrexate + in + Patients + With + Active + Rh eumatoid+Arthritis\&rank=1].

20. Morin C, Blier PU, Fortin S. Eicosapentaenoic acid and docosapentaenoic acid monoglycerides are more potent than docosahexaenoic acid monoglyceride to resolve inflammation in a rheumatoid arthritis model. Arthritis Res Ther 2015; 17:142. doi: 10.1186/s13075-015-0653-y.

21. Courtenay JS, Dallman MJ, Dayan AD, Martin A, Mosedale B. Immunisation against heterologous type II collagen induces arthritis in mice. Nature 1980; 283(5748): 666-68. doi: 10.1038/283666a0.

22. Yoo TJ, Kim SY, Stuart JM, Floyd RA, Olson GA, Cremer MA. et al. Induction of arthritis in monkeys by immunization with type II collagen. $\boldsymbol{J}$ Exp Med 1988; 168(2):777-82. doi: 10.1084/jem.168.2.777

23. Brand DD, Latham KA, Rosloniec EF. Collageninduced arthritis. Nat Protoc 2007; 2(5): 1269-75. doi: 10.1038/nprot.2007.173.

24. Nordquist N, Olofsson P, Vingsbo-Lundberg C, Petterson U, Holmdahl R. Complex genetic control in a rat model for rheumatoid arthritis. $\boldsymbol{J}$ Autoimmun 2000; 15(4):425-32. doi: 10.1006/jaut.2000.0450.

25. Cardiff RD, Miller CH, Munn RJ. Manual hematoxylin and eosin staining of mouse tissue sections. Cold Spring Harb Protoc 2014; 2014(6):655-58. doi: 10.1101/pdb.prot073411.

26. Sedlak J, Lindsay RH. Estimation of total proteinbound and non-protein sulfhydryl groups in tissues with Ellman's reagent. Anal Biochem 1968; 25(1):192-05. doi: 10.1016/0003-2697(68)900924.

27. Hadwan MH. New Method for Assessment of Serum Catalase Activity. Indian J Sci Technol 2016; 9(4):1-5. doi:10.17485/ijst/2016/v9i4/80499.

28. Kono Y. Generation of superoxide radical during autoxidation of hydroxylamine and an assay for superoxide dismutase. Arch Biochem Biophys 1978; 186(1):189-95. doi: 10.1016/00039861(78)90479-4.

29. Ohkawa H, Ohishi N, Yagi K. Assay for lipid peroxides in animal tissues by thiobarbituric acid reaction. Anal Biochem 1979; 95(2): 351-58. doi: 10.1016/0003-2697(79)90738-3.

30. Bastidas O. Cell counting with neubauer chamber, basic hemocytometer usage. Technical Note Neubauer Chamber Cell Counting 2013.

31. Gilmour D, Sykes AJ. Westergren and Wintrobe methods of estimating ESR compared. Br Med J 1951; 2(4746):1496-97. doi: 10.1136/bmj.2.4746.1496.

32. Zhang ZC, Zhang SJ, Jin B, Wu Y, Yang XF, Yu B. et al. Ciclamilast ameliorates adjuvant-induced arthritis in a rat model. BioMed Res Int 2015; 2015:786104. doi: 10.1155/2015/786104.

33. Dwivedi S. Oxidative Stress and Role of Antioxidant in Osteoarthritis \& Rheumatoid Arthritis: A Review Article. Int J Inno Res Dev 2014; 3: 225-236.

34. Quiñonez-Flores CM, González-Chávez SA, Del Río Nájera D, Pacheco-Tena C. Oxidative stress relevance in the pathogenesis of the rheumatoid arthritis: a systematic review. BioMed Res Int 2016; 2016:6097417. doi: 10.1155/2016/6097417.

35. Kundu S, Ghosh P, Datta S, Ghosh A, Chattopadhyay S, Chatterjee M. Oxidative stress as a potential biomarker for determining disease activity in patients with rheumatoid arthritis. Free Radic Res 2012; 46(12):1482-89. doi: 10.3109/10715762.2012.727991.

36. Gao B, Doan A, Hybertson BM. The clinical potential of influencing Nrf2 signaling in degenerative and immunological disorders. Clin Pharmacol 2014; 6:19-34. doi: 10.2147/CPAA.S35078.

37. Wruck CJ, Fragoulis A, Gurzynski A, Brandenburg LO, Kan YW, Chan K. et al. Role of oxidative stress in rheumatoid arthritis: insights from the Nrf2knockout mice. Ann Rheum Dis 2011; 70(5): 84450. doi: 10.1136/ard.2010.132720.

38. Brown PM, Pratt AG, Isaacs JD. Mechanism of action of methotrexate in rheumatoid arthritis, and the search for biomarkers. Nat Rev Rheumatol 2016; 12(12):731-42.

doi: 10.1038/nrrheum.2016.175. 